\title{
Algunos apuntes sobre la deducción de gastos de responsabilidad social para efectos del Impuesto a la Renta
}

\author{
Tania Albarracín Cabrera*
}

\begin{abstract}
Resumen. - En el Perú, existen empresas que, debido a sus actividades, en su mayoría extractivas, necesitan incurrir en una serie de gastos para poder llevar una relación cordial con las poblaciones y comunidades ubicadas en sitios aledaños al lugar donde tales empresas desarrollan sus operaciones y así evitar conflictos sociales que pongan en peligro la actividad de la empresa, así como la seguridad de sus activos y trabajadores. Estos gastos son necesarios para que las empresas puedan lograr su pleno, pacífico, normal y continuo funcionamiento, y por tanto, deben ser considerados como deducibles para efectos del Impuesto a la Renta. En el presente artículo se analizan tres posibles formas o regímenes para lograr esta deducción.
\end{abstract}

\begin{abstract}
In Peru, there are companies that, due to their activities, mostly extractive, need to make expenses in order to maintain a cordial relationship with the populations and communities located in places near the place where such companies carry out their operations and thus, avoid social conflicts that endanger the activity of the company as well as the safety of its assets and workers. These expenses are necessary so that companies can achieve their full, peaceful, normal, and continuous function, and therefore, they must be considered as deductible for Income Tax purposes. In this article, three possible ways or regimes to achieve this deduction are analyzed.
\end{abstract}

Palabras claves. - Gastos de responsabilidad social - Gastos por donaciones Mejoramiento de carreteras.

Keywords. - Social responsibility expenditures - Donation expenditures - Road improvement - Road maintenance.

* Abogada por la Pontificia Universidad Católica del Perú. Máster en Tributación por la Universidad de Georgetown. Asociada Senior del Estudio Zuzunaga, Assereto \& Zegarra Abogados. 


\section{Introducción}

En el Perú, las empresas que desean realizar actividades extractivas necesitan tener buenas relaciones con las poblaciones aledañas a los lugares donde desarrollarán tales actividades.

Se debe tener en cuenta que este tipo de actividades no suele realizarse cerca de las ciudades, sino que, más bien, se ejecutan en lugares alejados; en especial en la Sierra y Selva de nuestro país. Y es justamente en estos lugares alejados que la ausencia del Estado provoca en las poblaciones grandes expectativas ante la presencia de una empresa que va a desarrollar sus operaciones en zonas cercanas a donde ellas se encuentran establecidas.

Como es de público conocimiento, en caso estas expectativas no sean satisfechas, ello puede provocar conflictos entre las empresas y estas poblaciones que, en muchos casos, han derivado en toma de carreteras, destrucción de activos, secuestro de trabajadores de las empresas, entre otros hechos que buscan que estas expectativas sean atendidas ${ }^{1}$.

Es en este marco que varias de estas empresas cuentan con políticas corporativas de responsabilidad social, que las lleva a asumir ciertos costos para implementar proyectos y programas que promuevan el desarrollo económico y social de las localidades cercanas a las áreas en las que lleva a cabo sus actividades. La finalidad de implementar tales proyectos y programas tiene un enfoque preventivo. La idea es justamente evitar los impactos generados por el escalamiento de conflictos sociales, buscando un adecuado equilibrio con dicho entorno ambiental y social, al contar con el consenso social con la comunidad y el entorno en el que desarrolla respecto de las actividades de las empresas.

Al implementar estas políticas de responsabilidad social, se logra mantener una buena relación con la población, comunidades y autoridades de los distritos vinculados con la zona donde realizan sus actividades, y de esa manera les permite a las empresas identificar aquellas expectativas que se requieren satisfacer para lograr su pleno, pacífico, normal y continuo funcionamiento.

Para esto, se desarrollan e implementan diversos proyectos, sea directamente por la empresa o a través de terceros, privilegiando los temas más urgentes que hayan sido identificados como consecuencia de interactuar con las poblaciones. Se busca, de esa manera, lograr un desarrollo en términos sociales, culturales, económicos o de cualquier otra índole.

1 Al respecto, podemos mencionar diversos casos que son de público conocimiento toda vez que han sido materia de difusión en varios medios de comunicación masiva a nivel nacional e internacional. Es el caso, por ejemplo, del Proyecto Conga de la empresa minera Yanacocha, que tuvo que ser cerrado debido a las movilizaciones y acciones de las comunidades que se vieron afectadas por el mismo. Asimismo, podemos mencionar el Proyecto Tía María de la empresa Southern Perú que enfrentó diversas paralizaciones provocadas por las poblaciones de la zona. 
Asimismo, no puede perderse de vista que estas empresas tienen que cumplir con obligaciones contraídas con motivo del inicio o ejecución de sus actividades, tanto con el Estado Peruano a través de instrumentos tales como el Estudio de Impacto Ambiental, el Plan de Cierre de Minas, entre otros, así como con las poblaciones aledañas, a través de los acuerdos suscritos a través de Mesas de Diálogo, Actas de Compromiso, entre otros.

Ahora bien, dado que las empresas incurren en este tipo de desembolsos por necesidad para el buen funcionamiento de sus negocios, resulta necesario que los mismos puedan ser deducibles como gasto para efectos del Impuesto a la Renta.

En línea con lo antes señalado, en el presente trabajo mencionaremos tres formas o regímenes que podrían utilizar los contribuyentes para hacer deducibles tales desembolsos. Con este objetivo mencionaremos el tratamiento de los gastos por donaciones y gastos por infraestructura de servicio público, pero nos centraremos en la deducción de gastos que no tienen disposiciones especiales para su deducción pero que deben serlo debido a que cumplen con el principio de causalidad.

\section{Deducción de gasto por donaciones}

Cuando las poblaciones y/o comunidades con las que las empresas extractivas desean relacionarse, se encuentran representadas por organizaciones o entidades sin fines de lucro debidamente inscritas en los Registros Públicos de la zona, o están efectivamente lideradas por autoridades estatales (de cualquier estamento del sector público), es posible que las empresas extractivas canalicen sus aportes y ayudas a través de ellas.

Para tal efecto, las empresas pueden donar bienes a estas organizaciones y entidades para que éstas, a su vez, las entreguen a las poblaciones y comunidades. Este tipo de donaciones tiene un tratamiento especialmente previsto en las normas del Impuesto a la Renta que explicamos a continuación.

\section{i. La donación en materia civil}

Ahora bien, antes de siquiera empezar a ver el tratamiento tributario de estas donaciones, es necesario verificar que, en efecto, el acto del que estemos hablando sea una donación, de acuerdo con las normas del Código Civil del Perú.

Al respecto, mediante el artículo $1621^{\circ}$ del Código Civil se ha establecido que, “Por la donación el donante se obliga a transferir gratuitamente al donatario la propiedad de un bien". Asimismo, conforme a lo previsto en los artículos $1623^{\circ} \mathrm{y}$ $1624^{\circ}$ de dicho Código, la donación de bienes muebles cuyo valor supere el $25 \%$ de la UIT (S/1,100 en el ejercicio 2021), debe de realizarse por escrito de fecha cierta $^{2}$.

$2 \mathrm{Al}$ respecto, $\operatorname{los}$ artículos $1623^{\circ}$ y $1624^{\circ}$ establecen: 
En la misma línea, mediante el artículo $1625^{\circ}$ de dicho Código, se ha previsto que, la donación de bienes inmuebles debe realizase por escritura pública ${ }^{3}$.

En ese sentido, antes de verificar los requisitos previstos en materia tributaria para la deducibilidad de la donación, sobre los cuales nos ocupamos a continuación, resulta necesario que, se verifique el cumplimiento de las formalidades establecidas en las normas sobre la materia.

\section{ii. Impuesto a la Renta}

Al respecto, el inciso x) del artículo $37^{\circ}$ del Texto Único Ordenado de la Ley del Impuesto a la Renta, aprobado mediante Decreto Supremo N¹79-2004-EF (LIR), ha establecido que:

"A fin de establecer la renta neta de tercera categoría se deducirá de la renta bruta los gastos necesarios para producirla y mantener su fuente, así como los vinculados con la generación de ganancias de capital, en tanto la deducción no esté expresamente prohibida por esta ley, en consecuencia, son deducibles:

(...) x) Los gastos por concepto de donaciones otorgadas en favor de entidades y dependencias del Sector Público Nacional, excepto empresas, y de entidades sin fines de lucro cuyo objeto social comprenda uno o varios de los siguientes fines:(i) beneficencia; (ii) asistencia o bienestar social; (iii) educación; (iv) culturales; (v) científicos; (vi) artísticos; (vii) literarios; (viii) deportivos; (ix) salud; (x) patrimonio histórico cultural indígena; y otros de fines semejantes; siempre que dichas entidades y dependencias cuenten con la calificación previa por parte de la SUNAT. La deducción no podrá exceder del diez por ciento $(10 \%)$ de la renta neta de tercera categoría, luego de efectuada la compensación de pérdidas a que se refiere el artículo 50." (El resaltado es nuestro)

De las normas antes citadas se tiene que las donaciones serán deducibles de la renta bruta cuando sean causales y se realicen, entre otros, a favor de entidades y dependencias del Sector Público Nacional, así como organizaciones sin fines de lucro siempre que cuenten con la calificación previa por parte de la SUNAT y no excedan del $10 \%$ de la renta neta de tercera categoría de la empresa donante, luego de efectuada la compensación de pérdidas correspondiente.

\footnotetext{
“Artículo 1623.- La donación de bienes muebles puede hacerse verbalmente, cuando su valor no exceda del $25 \%$ de la Unidad Impositiva Tributaria, vigente al momento en que se celebre el contrato".

Artículo 1624.- Si el valor de los bienes muebles excede el límite fijado en el artículo 1623, la donación se deberá hacer por escrito de fecha cierta, bajo sanción de nulidad.

3 El artículo $1625^{\circ}$ establece que "La donación de bienes inmuebles, debe hacerse por escritura pública, con indicación individual del inmueble o inmuebles donados, de su valor real y el de las cargas que ha de satisfacer el donatario, bajo sanción de nulidad".
} 
Adicionalmente, mediante el inciso s) del artículo $21^{\circ}$ del Reglamento ${ }^{4}$ de la LIR (en adelante RLIR), se han establecido los requisitos específicos que deben ser cumplidos para que la donación resulte deducible. A continuación, mencionamos estos requisitos:

\begin{tabular}{|c|c|c|c|c|}
\hline $\begin{array}{c}\text { Donación } \\
\text { de: }\end{array}$ & Formalidad & $\begin{array}{l}\text { Valor de la } \\
\text { donación }\end{array}$ & $\begin{array}{c}\text { Debe } \\
\text { acreditarse } \\
\text { mediante }\end{array}$ & $\begin{array}{c}\text { Datos del } \\
\text { documento de } \\
\text { acreditación }\end{array}$ \\
\hline Dinero & $\begin{array}{l}\text {-Si el valor de } \\
\text { los bienes } \\
\text { muebles } \\
\text { excede el } 25 \% \\
\text { de la UIT, la } \\
\text { donación se } \\
\text { deberá hacer } \\
\text { por escrito de } \\
\text { fecha cierta, } \\
\text { bajo sanción } \\
\text { de nulidad } \\
\text {-Se debe } \\
\text { utilizar } \\
\text { medios de } \\
\text { pago }\end{array}$ & & $\begin{array}{l}\text { Acta de } \\
\text { entrega y } \\
\text { recepción del } \\
\text { bien donado } \\
\text { y una copia } \\
\text { autenticada } \\
\text { de la } \\
\text { resolución en } \\
\text { la que se } \\
\text { acepté la } \\
\text { donación }\end{array}$ & $\begin{array}{l}\text { - Los datos de } \\
\text { identificación del } \\
\text { donante: nombre } \\
\text { o razón social, } \\
\text { número de } \\
\text { Registro Único } \\
\text { de } \\
\text { Contribuyente, o } \\
\text { el documento de } \\
\text { identidad } \\
\text { personal que } \\
\text { corresponda, en } \\
\text { caso de carecer } \\
\text { de RUC. } \\
\text { - La fecha de la } \\
\text { donación }\end{array}$ \\
\hline $\begin{array}{l}\text { Bienes } \\
\text { inmuebles }\end{array}$ & $\begin{array}{l}\text { Debe realizarse } \\
\text { por escritura } \\
\text { pública, con } \\
\text { indicación } \\
\text { individual del } \\
\text { inmueble } \\
\text { donado, de su } \\
\text { valor real y de } \\
\text { las cargas que } \\
\text { ha de satisfacer } \\
\text { el donatario, } \\
\text { bajo sanción de } \\
\text { nulidad }\end{array}$ & $\begin{array}{l}\text { No puede } \\
\text { ser en } \\
\text { ningún } \\
\text { caso } \\
\text { superior al } \\
\text { costo } \\
\text { computable }\end{array}$ & $\begin{array}{l}\text { Acta de } \\
\text { entrega y } \\
\text { recepción del } \\
\text { bien donado } \\
\text { y una copia } \\
\text { autenticada } \\
\text { de la } \\
\text { resolución en } \\
\text { la que se } \\
\text { acepté la } \\
\text { donación }\end{array}$ & $\begin{array}{l}\text { - Los datos de } \\
\text { identificación del } \\
\text { donante: nombre } \\
\text { o razón social, } \\
\text { número de } \\
\text { Registro Único } \\
\text { de } \\
\text { Contribuyente, o } \\
\text { el documento de } \\
\text { identidad } \\
\text { personal que } \\
\text { corresponda, en } \\
\text { caso de carecer } \\
\text { de RUC. } \\
\text { - Los datos que } \\
\text { permitan } \\
\text { identificar el bien } \\
\text { donado, su valor, } \\
\text { estado de } \\
\text { conservación, así } \\
\text { como la fecha de } \\
\text { la donación. }\end{array}$ \\
\hline
\end{tabular}

4 Aprobado mediante Decreto Supremo N²122-94-EF publicado el 21 de setiembre de 1994 y normas modificatorias. 


\begin{tabular}{|c|c|c|c|c|}
\hline $\begin{array}{l}\text { Bienes } \\
\text { muebles }\end{array}$ & $\begin{array}{l}\text { Si el valor de } \\
\text { los bienes } \\
\text { muebles excede } \\
\text { el 25\% de la } \\
\text { UIT, la } \\
\text { donación se } \\
\text { deberá hacer } \\
\text { por escrito de } \\
\text { fecha cierta, } \\
\text { bajo sanción de } \\
\text { nulidad. En el } \\
\text { instrumento } \\
\text { deben } \\
\text { especificarse y } \\
\text { valorizarse los } \\
\text { bienes que se } \\
\text { donen. }\end{array}$ & $\begin{array}{l}\text { No puede } \\
\text { ser en } \\
\text { ningún } \\
\text { caso } \\
\text { superior al } \\
\text { costo } \\
\text { computable }\end{array}$ & $\begin{array}{l}\text { Acta de } \\
\text { entrega y } \\
\text { recepción del } \\
\text { bien donado } \\
\text { y una copia } \\
\text { autenticada } \\
\text { de la } \\
\text { resolución en } \\
\text { la que se } \\
\text { acepté la } \\
\text { donación }\end{array}$ & 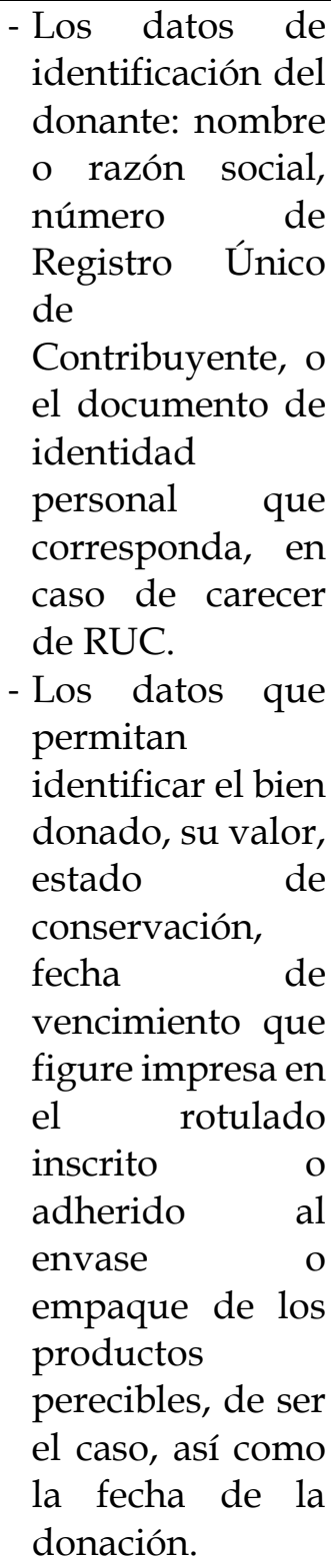 \\
\hline
\end{tabular}

\begin{tabular}{|l|l|}
\hline $\begin{array}{c}\text { Donación } \\
\text { de: }\end{array}$ & \multicolumn{1}{c|}{ Ejercicio en que podrá deducirse el gasto } \\
\hline Dinero & Cuando se entregue el monto al donatario \\
\hline $\begin{array}{l}\text { Bienes } \\
\text { inmuebles }\end{array}$ & Cuando la donación conste en escritura pública \\
\hline $\begin{array}{l}\text { Bienes } \\
\text { muebles }\end{array}$ & $\begin{array}{l}\text { Bienes muebles registrables, cuando la donación conste en un } \\
\text { documento de fecha cierta en el que se identifique el bien } \\
\text { donado, su valor y el de las cargas que ha de satisfacer el } \\
\text { donatario }\end{array}$ \\
& $\begin{array}{l}\text { Títulos valores, cuando éstos sean cobrados; y, } \\
\text { Otros bienes muebles, cuando la donación conste en un } \\
\text { documento de fecha cierta en el que se especifiquen sus } \\
\text { características, valor y estado de conservación. Se dejará } \\
\text { constancia de la fecha de vencimiento que figure en el }\end{array}$ \\
\hline
\end{tabular}


\begin{tabular}{|l|l|}
\hline & $\begin{array}{l}\text { rotulado inscrito o adherido al envase o empaque de los } \\
\text { productos perecibles, de ser el caso. }\end{array}$ \\
\hline
\end{tabular}

Fuente: Elaboración propia

Ahora bien, repetimos que esta forma de deducción será de utilidad en tanto la empresa se encuentre con que las poblaciones y comunidades aledañas a su lugar de explotación sienten que están debidamente representadas por las autoridades estatales del lugar (en especial gobiernos locales) y/o por las entidades sin fines de lucro (como asociaciones) que operan en el sitio, puesto que de no ser así, no quedará más que realizar estas entregas o donaciones directamente a las comunidades, lo que no habilita a utilizar lo señalado en el inciso x) del artículo $37^{\circ}$ de la LIR antes comentado.

Asimismo, en caso de que la empresa no tenga ingresos en determinado año, tendrá como consecuencia que perderá el gasto por lo donado siguiendo las reglas de la referida norma, que prevé que la deducción no podrá exceder del diez por ciento $(10 \%)$ de la renta neta de tercera categoría de la empresa.

En tal sentido, a continuación, analizamos otros supuestos de deducción de los gastos bajo comentario.

\section{Deducción de gasto por inversiones en infraestructura}

De acuerdo con lo dispuesto en el artículo $72^{\circ}$ inciso d) de la Ley General de Minería $^{5}$ (LGM), las inversiones que efectúen los titulares de la actividad minera en infraestructura que constituyan servicio público, serán deducibles de la renta imponible, siempre que las inversiones hubieren sido aprobadas por el organismo del sector competente.

Al respecto, el reglamento ${ }^{6}$ de la referida ley señala que el concepto de infraestructura de servicio público comprende entre otras, las obras viales, puertos, aeropuertos, obras de saneamiento ambiental, obras e instalaciones de energía, telecomunicaciones, salud, educación, recreación e infraestructura urbana. Se indica, además, que se considera que tales obras e inversiones constituyen servicio público, cuando puedan ser utilizadas por la colectividad organizada.

Para tal efecto, el mismo reglamento establece que la deducción de la renta imponible de estas inversiones sólo procederá en la proporción destinada a brindar servicio público, lo que deberá constar en la respectiva resolución de aprobación.

5 Según el Texto Único Ordenado aprobado por Decreto Supremo Nº 014-92-EM, publicado el 04 de junio de 1992 y normas modificatorias.

6 Artículo $7^{\circ}$ del Decreto Supremo Nº24-93-EM publicado el 07 de junio de 1993. 
En cuanto al procedimiento, la norma reglamentaria7 indica que el titular de actividad minera deberá presentar a la Dirección General de Minería una memoria descriptiva, presupuesto y cronograma de la inversión que se proponga realizar en infraestructura de servicio público. Se indica, además, que la Dirección General de Minería, dentro de los cinco días calendario siguientes a su recepción, bajo responsabilidad, remitirá dicho programa al Sector competente, el cual, en un plazo de treinta días calendario, contado a partir de la fecha de su recepción, resolverá sobre el mismo.

Es del caso mencionar que, mediante Resolución Ministerial № 577-2007-MTC-028, el Ministerio de Transportes y Comunicaciones (MTC) aprobó el Procedimiento de aprobación de inversiones en infraestructura vial de servicio público realizadas por empresas mineras, aplicable para la revisión de proyectos de inversiones presentados por los titulares de la actividad minera en infraestructura vial de servicio público de caminos, carreteras y ferrocarriles. En esta norma se describe el procedimiento interno que deban seguir los diversos órganos que componen el referido Ministerio, de acuerdo con las funciones que se establecen en su Reglamento de Organización y Funciones, para proceder con la evaluación y aprobación de las inversiones 9 .

Cabe señalar que el MTC, mediante el Oficio No 041-2004-MTC/14 e Informe $\mathrm{N}^{\mathrm{o}}$ 001-2004-MTC/14.03, señaló que las inversiones en infraestructura que constituya servicio público no comprenden el mantenimiento de carreteras, pues éste no califica como obra vial de infraestructura. Agrega, que el concepto de obras viales está referido al proceso de materializar la infraestructura de las carreteras, ferrocarriles y viaductos.

Como se puede apreciar, la LGM y su reglamento tiene previsto un procedimiento establecido para que una empresa minera que invierta en infraestructura de servicio público pueda deducir los costos de su inversión para efectos del Impuesto a la Renta. Así también, tratándose de obras de infraestructura vial, el MTC ha establecido un procedimiento para la aprobación de este tipo de inversiones. Por lo tanto, corresponde preguntarse si este procedimiento realmente ha resultado útil a lo largo de los años.

A tal efecto, debemos tener en cuenta que la LGM prevé este procedimiento desde el año 1992, es decir, hace casi 29 años, mientras que el procedimiento del MTC ha fijado su procedimiento interno desde el año 2007, esto es, hace ya 14 años. No obstante, a la fecha no hemos tomado conocimiento de más de un único caso aprobado justamente por el MTC. Se trata de la Resolución Viceministerial N6092008-MTC/0210, de fecha 14 de julio de 2008. Mediante esta resolución se aprobó

Artículo $8^{\circ}$ del mismo reglamento.

Publicado el 08 de octubre de 2007.

9 Debemos mencionar que no tenemos conocimiento de que otro ministerio haya establecido un procedimiento de esta naturaleza para la aprobación de inversiones de infraestructura según lo establecido en la LGM.

10 Obtenida mediante solicitud de acceso a la información pública presentada ante el MTC. 
la inversión vial relativa al Proyecto "Rehabilitación y Mejoramiento de la Carretera Chilete - San Pablo - Empalme Ruta 3N Km. 25 (Carretera Cajamarca Bambamarca)", efectuada por la empresa Minera Yanacocha S.R.L. En esta resolución se fija en $100 \%$ la proporción de la infraestructura vial destinada a brindar servicio público del referido proyecto.

De nuestra experiencia, aun cuando este procedimiento se encuentra reglamentado, en la práctica, resulta bastante engorroso de cumplir, motivo por el cual las empresas mineras no suelen recurrir al mismo cuando necesitan realizar inversiones en infraestructura cuando así lo requieren, por ejemplo, las comunidades o poblaciones aledañas al sitio de la mina.

Ante ello, algunos señalarán que justamente por ese motivo existe ya otra opción como es hacer este tipo de obras de infraestructura mediante la alternativa de obras de impuestos ${ }^{11}$. Sobre esto último, si bien no es parte del presente trabajo analizar esta opción, debe tenerse presente que la misma implica la celebración de convenios entre empresas privadas y entidades del Sector Público para financiar o ejecutar, con cargo a futuros fondos públicos, proyectos de inversión, a cambio de una retribución materializada en un documento representativo de deuda pública denominado Certificado de Inversión Pública. Esta sería una opción bastante segura pensando en una futura probanza, sin embargo, debe tenerse presente que también implica seguir un procedimiento de varios pasos, que la empresa deberá analizar si vale la pena seguir dependiendo del tamaño de la inversión en infraestructura que se tiene pensado realizar.

\section{Deducción de gasto por causalidad}

Ahora bien, de la práctica, se tiene que no siempre lo que debe entregar o prestar una empresa extractiva o lo que las comunidades le solicitan, está vinculado con obras de infraestructura a las que se les pueda aplicar el régimen dispuesto en la LGM antes mencionado. Como indicamos anteriormente puede pasar que estas poblaciones no están organizadas en entidades sin fines de lucro debidamente inscritas en registros públicos, así también puede suceder que estas comunidades no se sientan representadas por las autoridades locales ni por otro funcionario estatal de la zona, con lo cual no se puede recurrir a éstos para canalizar las ayudas. En estos casos la empresas deberá coordinar directamente con los representantes de las comunidades a efectos de conocer sus necesidades y requerimientos con miras a implementar proyectos y programas que satisfagan las expectativas de dichas comunidades y así poder llevar buenas relaciones con la comunidad.

Así, corresponde que las empresas entreguen bienes y servicios directamente a las comunidades y sus pobladores con la finalidad de lograr la paz social y poder

11 Según lo normado en el Decreto Supremo N²94-2018-EF, Texto Único Ordenado de la Ley Nº 29230, Ley que impulsa la inversión pública regional y local con participación del Sector Público; la Ley $\mathrm{N}^{\circ}$ 30264, Ley que establece medidas para promover el crecimiento económico, y normas reglamentarias. 
ejecutar sus actividades con normalidad.

De esa manera, las mencionadas entregas de bienes y servicios no se realizarían sin un objetivo, sino que, por el contrario, están asociadas estrechamente a permitir que las empresas puedan continuar produciendo rentas gravadas, así como para proteger las instalaciones que permiten que se puedan producir tales rentas. En tal sentido, corresponde analizar si los desembolsos vinculados con las mismas pueden ser deducidos como gasto para efectos del impuesto a la renta.

\section{i. El principio de causalidad}

De acuerdo con la LIR, para que un desembolso pueda ser aprovechado tributariamente (esto es, sea calificado como un costo o gasto deducible para efectos de determinar la renta neta imponible del citado impuesto), el mismo debe encontrarse vinculado con la generación de rentas gravadas -incluyendo las ganancias de capital- o con el mantenimiento de su fuente productora; lo que se conoce como "principio de causalidad", de conformidad con el primer párrafo del artículo $37^{\circ}$ de la $\operatorname{LIR}^{12}$.

Para tal efecto, debe entenderse que los gastos cumplen con este principio cuando sean "normales para la actividad que genera la renta gravada, así como cumplir con criterios tales como razonabilidad en relación con los ingresos del contribuyente $(\ldots)^{\prime \prime}$, de acuerdo con la Tercera Disposición Final de la Ley $\mathrm{N}^{\mathrm{o}}$ 27356.

Ahora bien, la LIR recoge el Principio de Causalidad, como regla general para admitir la deducibilidad o no de los gastos, siendo admisibles aquellos que guarden una relación con la generación de la renta gravada o con el mantenimiento de la fuente en condiciones de productividad, que sean gastos normales de acuerdo con el giro del negocio o que guarden cierta proporción con el volumen de las operaciones y que sean razonables en relación con los ingresos del recurrente.

En este sentido, se pronuncia García Mullin13 cuando señala que "del propio principio de causalidad surgen implícitos algunos de los caracteres que deben revestir los gastos para ser deducibles: ser necesarios (algunas legislaciones hablan de 'imprescindibles') para obtener o mantener la fuente; ser normales de acuerdo con el giro del negocio, mantener cierta proporción con el volumen de operaciones, etc.".

12 Artículo 37.- A fin de establecer la renta neta de tercera categoría, se deducirá de la renta bruta los gastos necesarios para producirla y mantener su fuente, así como los vinculados con la generación de ganancias de capital, en tanto la deducción no esté expresamente prohibida por esta ley."

13 GARCÍA MULLIN, Juan Roque. Impuesto sobre la Renta. Teoría y Técnica del Impuesto. Santo Domingo. Instituto de Capacitación Tributaria, 1980. pág. 122. 
Ahora bien, el Tribunal Fiscal en reiterada jurisprudencia, tales como las Resoluciones $N^{\circ} 710-2-99$ y 1275-2-2004 ha considerado lo siguiente:

"Principio de Causalidad es la relación de necesidad que debe establecerse entre los gastos y la generación de renta o el mantenimiento de la fuente, noción que en nuestra legislación es de carácter amplio pues se permite la sustracción de erogaciones que no guardan dicha relación de manera directa; no obstante ello, el Principio de Causalidad debe ser atendido, por lo cual para ser determinado deberán aplicarse criterios adicionales como que los gastos sean normales de acuerdo al giro del negocio o éstos mantengan cierta proporción con el volumen de las operaciones, entre otros".

Conforme a lo expuesto, se desprende que los gastos normales y necesarios a los que se refiere la norma citada, así como la jurisprudencia fiscal vinculada a la generación de la renta gravada y al mantenimiento de la fuente, son aquellos en los que la empresas incurren cotidianamente, o en forma concurrente $\mathrm{y}$, todos aquéllos que cumpliendo o no con los dos criterios anteriores, responden a decisiones empresariales vinculadas directa o indirectamente a la generación de ingresos, siempre y cuando su deducción no se encuentre expresamente prohibida por las normas del Impuesto a la Renta.

En consecuencia, se entiende que los gastos necesarios y normales, es decir, los que son deducibles a efectos tributarios, no son únicamente los típicos incurridos en el desarrollo ordinario de las actividades empresariales, sino también aquellos atípicos que, directa o indirectamente, tengan por objeto la obtención de beneficios para la empresa, vale decir que cumplan con el principio de causalidad, como son los gastos por responsabilidad social.

Ahora bien, para analizar cómo se ha venido pronunciando la SUNAT, el Tribunal Fiscal y el Poder Judicial sobre este tipo de gastos, los separaremos en dos grupos: el primero conformado por pronunciamientos sobre la entrega de bienes y servicios diversos en general y el segundo conformado por pronunciamientos sobre mantenimiento y mejoramiento de canales, caminos y carreteras.

\section{ii. Entrega de bienes y servicios diversos}

\section{A. Gastos considerados como liberalidad}

En cuanto a la entrega de bienes y servicios diversos hemos identificado un primer grupo de pronunciamientos en los cuales el Tribunal Fiscal, mediante las Resoluciones N7263-1-2004, 01932-5-2004, 4807-1-2006, 013558-3-2009, 09478-1-2013, entre otras, consideró que los gastos de responsabilidad social no cumplían con el principio de causalidad, por lo que calificaban como actos de liberalidad, de acuerdo con lo establecido en el inciso d) del artículo $44^{\circ}$ del RLIR.

No obstante, cabe precisar que ya en el año 2005, mediante la Resolución Nº1424-5-2005, el Tribunal Fiscal precisó que resultaba razonable que las 
empresas que se dedican a actividades mineras adquieran insumos para el cuidado o tratamiento de tierras agrícolas como parte de sus programas de responsabilidad social y protección del medio ambiente.

B. Gastos para evitar conflictos

Un segundo grupo identificado es aquel que reúne resoluciones en las que, tanto el Tribunal Fiscal como el Poder Judicial precisaron que los gastos vinculados a la adquisición de bienes y servicios otorgados o prestados a las comunidades próximas al área de operaciones de una empresa eran deducibles, toda vez que los mismos se realizan a efectos de evitar conflictos sociales que puedan afectar el normal desarrollo de las operaciones de la empresa.

En efecto, mediante diversas resoluciones, que iremos desarrollando más adelante, el Tribunal Fiscal reconoció la deducibilidad de dichos gastos. Asimismo, precisó que los gastos efectuados por concepto de responsabilidad social corporativa no constituyen meros actos de liberalidad, sino, por el contrario, instrumentos legítimos utilizados por las empresas para la generación y/o mantenimiento de sus ingresos, y también de la respectiva fuente productora.

Adicionalmente, el Poder Judicial, mediante las Casaciones N²565-2008, 2743-2009, y 133-2015, establece que los gastos efectuados en beneficio de integrantes de comunidades nativas aledañas a los lugares de operaciones de una empresa son necesarios y causales, toda vez que, de no efectuarse, se puede entorpecer las actividades de la misma.

En ese sentido, el Tribunal Fiscal, en la Resolución N 10983-9-2019, en un caso en el que la recurrente señalaba que había entregado panetones y juguetes para evitar conflictos sociales, señaló lo siguiente:

“Que de lo expuesto se tiene que los gastos efectuados por concepto de responsabilidad social no constituyen meros actos de liberalidad sino por el contrario instrumentos legítimos utilizados por las empresas para la generación y mantenimiento de sus ingresos con el objetivo que los servicios contratados se orienten a favorecer las relaciones públicas entre la recurrente y la población donde desarrollan sus actividad generadora de renta y en este sentido tales erogaciones debidamente acreditadas y sustentadas se enmarcan dentro del principio de causalidad a qué se refiere el primer párrafo del artículo 37 dela ley del impuesto a la renta.

Que estando a que la Administración indica haber verificado que los panetones y juguetes cuyas compras observó fueron destinadas a la población de las comunidades (...) que se ubican a los alrededores donde la recurrente realiza sus operaciones empresariales y suponen acciones que tienen por objeto mantener las buenas relaciones entre la empresa la 
comunidad y su entorno las que a su vez redundan en la continuidad de sus operaciones generadoras de renta gravable se concluye que aquella califican como gastos efectuados por concepto de responsabilidad social corporativa careciendo de sustento lo señalado por la administración en sentido contrario"

Así, podemos mencionar a un grupo numeroso de resoluciones ${ }^{14}$, referidas a una conocida empresa petrolera en su actuación directa o a través de su participación a través de un consorcio, en las que el Tribunal Fiscal acepta la deducción de los gastos por entrega de diversos bienes y servicios a comunidades nativas aledañas al lugar donde se encontraba su yacimiento, pues tales entregas tenían como finalidad evitar conflictos sociales.

De entre esas resoluciones, creemos que vale la pena mencionar las Resoluciones $N^{\circ}$ 016591-3-2010, 07709-9-2018 y 00463-10-2016 mediante las cuales el Tribunal señala lo siguiente:

“Que (...) contrariamente a lo sostenido por la Administración Tributaria, el principio de causalidad no puede ser analizado de una forma restrictiva sino más bien amplia, comprendiendo en él todo gasto que guarde relación no solo con la producción de rentas, sino con el mantenimiento de la fuente, siendo que esta relación puede ser directa o indirecta, debiendo analizarse en este último caso conforme con los principios de razonabilidad y proporcionalidad.

Que así, en el caso de autos, esta instancia considera que los gastos efectuados por la recurrente no respondieron a una simple liberalidad, puesto que no se realizaron sin que se buscara con ello una finalidad concreta, sino que por el contrario, fueron realizados a efecto de evitar conflictos sociales que directamente pudieran afectar el normal funcionamiento de su yacimiento y demás instalaciones, siendo importante mencionar que si bien en el periodo objeto de autos no se habría producido la toma de los pozos petroleros, por las características de la actividad desarrollada por la recurrente y de la zona en que esta se efectuaba, tal posibilidad era patente, tal es así que en periodos posteriores ello se produjo, habiendo motivado la paralización de las actividades productivas de la recurrente e incluso la intervención de representantes del Gobierno Central, la Defensoría del Pueblo y de la sociedad civil con la finalidad de solucionar la situación de conflicto"(El resaltado es nuestro).

14 Como por ejemplo las Resoluciones N016591-3-2010, 14207-10-2014, 00463-10-2016, 02503-12017, 10534-9-2018, 07822-9-2018, 07709-9-2018, 07434-9-2018, 06830-9-2018, 06662-9-2018, 049479-2018, 07223-3-2018, 07234-3-2018, 07768-1-2018, 5433-1-2018, 05607-3-2018, 00431-3-2018, 081821-2018, 08376-9-2019, 06585-9-2019, 02546-9-2019, 09185-4-2019, 02120-4-2019, 00856-3-2019, 06745-3-2019, 00690-3-2019, 05551-1-2019, 01312-1-2019, 8302-9-2019, 06551-4-2019, 02877-1-2019 entre otras. 
Así también, en la Resolución № 07223-3-2018, citando lo señalado por el Tribunal Constitucional en el Exp. 0048-2004-PI/TC del 01/04/2005, se indica:

"El desarrollo sostenible o sustentable requiere de la responsabilidad social ello implica la generación de actitudes y comportamientos de los agentes económicos y el establecimiento de políticas de promoción y el desarrollo de actividades que en función del aprovechamiento y uso de los bienes ambientales procuren el bien común y el bienestar general a la vez que agregó que en el marco del Estado social y democrático de derecho de la economía social de Mercado y del desarrollo sostenible la responsabilidad se constituye en una conducta exigible a las empresas de forma ineludible

Asimismo, cabe precisar que, a diferencia de otros casos resueltos por el Tribunal Fiscal citados por la Administración, en el presente caso los gastos realizados tienen destinatarios concretos e identificados que pertenecen a las comunidades nativas involucradas en los conflictos sociales, lo que evidencia el interés de la recurrente en efectuar las erogaciones objeto de reparo a fin de mantener el normal desarrollo de sus actividades en los pozos o yacimientos".

\section{Posición de la SUNAT}

Ahora bien, para analizar cómo se ha venido pronunciando la SUNAT, el Tribunal Fiscal y el Poder Judicial sobre este tipo de gastos, los separaremos en dos grupos: el primero conformado por pronunciamientos sobre la entrega de bienes y servicios diversos en general y el segundo conformado por pronunciamientos sobre mantenimiento y mejoramiento de canales, caminos y carreteras.

No obstante que, a la fecha, se cuenta con numerosas resoluciones del Tribunal Fiscal que se pronuncian en el sentido antes mencionado, esto es, que se debe permitir la deducción de gastos por entrega de bienes y servicios a las comunidades para evitar posibles conflictos, debemos llamar la atención que la SUNAT, a pesar de ello, continúa teniendo una posición contraria al mismo. Así, por ejemplo, en la Resolución N 06745-3-2019, se recoge la posición de la SUNAT, que según se aprecia señala lo siguiente:

“(...) la recurrente contabilizó como gasto, desembolsos o erogaciones voluntarias realizadas por la entrega de bienes y por servicios realizados a favor de comunidades nativas asociaciones $o$ federaciones representativas de dichas comunidades y pobladores de las zonas de influencia de los contratos de producción petroleros aledañas a los lotes 56 y 88 los cuales constituyen actos de liberalidad dado que si bien la contribuyente señaló que los gastos reparados constituían gastos necesarios para evitar que los pobladores entorpezcan la realización de 
sus operaciones en sus instalaciones petroleras no acreditó dicha información con documentación competente como denuncia policial o pedido de intervención fiscal que acredite la existencia del riesgo de paralización de sus operaciones habituales sin embargo aun cuando la contribuyente hubiera acreditado ello no se aprecia la existencia de una obligación legal o contractual asumida por esta respecto a dichas comunidades por lo que no existe una relación de causalidad entre el concepto reparado y la generación de renta gravada o el mantenimiento de la Fuente no existiendo conexión alguna entre el giro de la contribuyente ( exploración y explotación comercial del petróleo) y la la prestaciones gratuitas por cuenta propia a los habitantes de las comunidades nativas por lo que concluye que los desembolsos efectuados no cumplen con el principio de causalidad y deben ser calificados como actos de liberalidad". (el resaltado es nuestro)

De igual manera, en la Resolución Nº 10983-9-2019, se aprecia que la SUNAT tenía el siguiente criterio:

“(...) la entrega de juguetes y panetones a las comunidades constituyen un acto de liberalidad por lo que su deducción no sería permitida para efectos del impuesto a la renta y que si bien la recurrente alega que la donación de los bienes antes descritos le permitió ejecutar sus labores en un ambiente de tranquilidad social así como a asumir los costos correspondientes a los daños del medio ambiente como parte del cumplimiento de su responsabilidad social como empresa minera no se acreditó que estuviera en riesgo la tranquilidad social de manera que existieran peligros de paralización de sus operaciones $\mathbf{u}$ otra forma que afectará su producción, ni existe en nuestro ordenamiento jurídico nacional obligación legal respecto de la entrega de bienes a título gratuito favor de comunidades beneficiadas" (el resaltado es nuestro)

Como se puede apreciar de las citas antes mencionadas, la SUNAT, si bien acepta que pueden existir desembolsos vinculados con entregas de bienes y servicios a las comunidades a fin de evitar conflictos, exige, que se pruebe que la empresa cuestionada muestre evidencias de que en realidad se encontraba ad-portas de un conflicto o bajo alguna clase de amenaza. Al respecto, debe tenerse presente que, si bien en muchos casos este tipo de amenazas e indicios salen publicadas en las noticias, existen también muchos otros en los que no es posible documentarlas. Además, en la práctica, los miembros de las comunidades no envían a las empresas cartas firmadas en las que comuniquen sus intenciones de cerrar una carretera o secuestrar ingenieros, por ejemplo. Asimismo, debe considerarse que, en la mayoría de los casos, no es posible contar con presencia policial en la zona y mucho menos es factible contar con la presencia de un fiscal que pueda acreditar la amenaza o el riesgo a que se ve sometida la empresa. En tal sentido, consideramos que debe tenerse en cuenta la potencialidad del conflicto, 
debido al tipo de actividad que realiza la empresa extractiva, al momento de evaluar la deducción de los gastos.

D. Gastos por cumplimiento de obligaciones

También se observa que el Tribunal Fiscal considera que, de acuerdo a lo establecido en el primer párrafo del artículo $37^{\circ}$ de la LIR, son deducibles los gastos de responsabilidad social vinculados a: (i) mitigación, (ii) obligaciones establecidas en el Estudio de Impacto Ambiental, (iii) obligaciones legales de la empresa como convenios con las comunidades, (iv) obligaciones establecidas en el plan de cierre de minas y (v) políticas de responsabilidad social.

Así, por ejemplo, tenemos el caso analizado en la Resolución № 07676-32019, en el cual una empresa petrolera aducía que "dentro de su plan de manejo ambiental se reveló el plan de relaciones comunitarias del proyecto en el cual se considera o que, por la ubicación y naturaleza de la prospección sísmica, las actividades de exploración afectarían a los pobladores y pescadores de las caletas y centros poblados", lo cual se veía básicamente en la rotura de redes de pesca, por lo que se veía obligada a indemnizar a los pescadores por las redes rotas.

$\mathrm{Al}$ respecto, la SUNAT no aceptó la deducción de dicho gasto señalando que no formaba parte de una política indicando que "un gasto de responsabilidad social (...) supone necesariamente el diseño, implementación y ejecución por parte de la empresa de programas integrales que tengan como finalidad el desarrollo económico y social de la comunidad local adyacente a sus centros productivos con la finalidad de mitigar cualquier contingencia y conflicto social"

Sobre el particular, el Tribunal Fiscal levanta el reparo luego de analizar el contenido del plan de relaciones comunitarias de la empresa, señalando lo siguiente:

"Qué del contenido del citado estudio se concluye que las erogaciones materia de cuestionamiento sí formaban parte de un conjunto de políticas o programas que conlleven al bienestar económico y social de los pescadores dentro del área de influencia del proyecto (...) los cuales resultaban de obligatorio cumplimiento para la recurrente y las comunidades y o gremios de pescadores ubicados en el área de influencia del proyecto tal como se aprecia de los reportes institucionales de entidades públicas proporcionados por la recurrente".

Así también, resulta importante mencionar la Resolución № 11000-1-2017, en la cual la empresa recurrente presentó como documentación de sustento de sus gastos por responsabilidad social, entre otros, el Estudio de Impacto Ambiental, planes de relaciones comunitarias, programas de inversión 
social, Resumen de los proyectos sociales ejecutados en el área de influencia, Memoria Anual de la empresa, Procedimiento de donaciones y gastos en gestión social (inversión social) que establece los lineamientos adoptados para gestionar sus procesos de donaciones y gastos de gestión social, Convenios de donación con las comunidades, actas de entrega y cartas de agradecimiento de las comunidades.

En ese caso, el Tribunal Fiscal procede a analizar cada entrega, siendo que cuando la misma formaba parte de la política de responsabilidad social y dentro del área de influencia, aceptaba su deducción. Del mismo modo se acepta la deducción cuando mediaban convenios de donación con la comunidad. Así, se acepta la deducción de gastos por bandas de música, talleres de desarrollo de capacidades, medicinas, agua mineral, entre otros.

E. Acreditación de las entregas

Ahora bien, teniendo claro que los gastos de responsabilidad social son deducibles en aplicación del principio de causalidad, no debe perderse de vista que, para que se permita su deducción, resulta necesario que las empresas que incurren en este tipo de gastos cuenten con la documentación sustentatoria necesaria para cada caso que demuestre que se incurrió efectivamente en este tipo de gastos.

Debe recordarse que, según lo señalado por el Tribunal Fiscal en diversas resoluciones, como por ejemplo en las $\mathrm{N}^{\circ}$ s 2411-4-96 y 2439-4-96, para que un gasto sea deducible se requiere documentación que acredite fehacientemente el destino del gasto y, de ser el caso, su beneficiario. En ese sentido, se señala que deberá sustentarse que realmente existió la operación, así como, presentarse documentación sustentatoria adicional respecto al destino del gasto. Agrega que, bajo este esquema se encuentran, por ejemplo, los contratos celebrados con clientes de la empresa, guías de remisión que acrediten el destino de los obsequios, libros contables en los cuales figure el registro de gastos, comunicaciones epistolares entre la empresa y su cliente. Menciona también documentos sustentatorios como cartas, e-mail, fax, informes enviados o recibidos, cheques emitidos, entre otros.

Cabe agregar que, en abundantes pronunciamientos, como el contenido en la Resolución N 07374-2-2007, el Tribunal Fiscal ha dejado establecido que para tener derecho a la deducción de gastos, no basta con acreditar que se cuenta con los comprobantes de pago que cumplen con los requisitos sustanciales y formales establecidos en las normas y respalden las operaciones realizadas ni demostrar su registro contable, sino que fundamentalmente es necesario acreditar que dichos comprobantes en efecto correspondan a operaciones reales o existentes, es decir, que se hayan producido en la realidad. 
Asimismo, en las Resoluciones del Tribunal Fiscal Ns 120-5-2002 y 3708-12004, se ha señalado que los contribuyentes deben mantener al menos un nivel mínimo indispensable de elementos de prueba que acrediten que los comprobantes que sustentan su derecho correspondan a operaciones reales.

Teniendo esto en mente, corresponde analizar con qué tipo de documentos debería contar una empresa para acreditar no solo que tenía derecho al gasto, esto es que cumple el principio de causalidad, sino que efectivamente incurrió en él.

Al respecto, el Tribunal Fiscal ha sido consistente en solicitar que se acredite la entrega efectiva de los bienes o servicios a las comunidades, sea mediante actas de entrega, cartas de requerimientos y agradecimientos, acuerdos suscritos por ambas partes a la entrega de los bienes, planillones en los que figure la asistencia de pobladores a cursos y talleres, constancias de recepción, actas de verificación levantadas por jueces de paz, informes de entidades estatales en las que se dé cuenta de las actividades realizadas por la empresa, listados en los que figure la firma y/o huella digital de pobladores al recibir bienes, entre otros.

Así por ejemplo, en la Resolución N 05150-11-2018, respecto de diversos servicios prestados a la Comunidad de Andahuasi, el Tribunal Fiscal aun cuando no cuestiona que ese tipo de gastos pueda ser causal para la empresa, no levantó el reparo efectuado por la SUNAT pues señaló que "la recurrente no ha presentado durante la fiscalización las pruebas fehacientes adicionales a los registros contables que acrediten que los gastos reparados fueron destinados efectivamente a la comunidad de Andahuasi"

Lo mismo sucede en la Resolución N 11000-1-2017, antes mencionada, en la cual el Colegiado analiza cada uno de los desembolsos efectuados por la empresa a favor de las comunidades, tomando en cuenta no solo la documentación que acredita la obligación de entrega, sino también que se pueda verificar en cada caso, la efectiva entrega de los bienes y servicios a los miembros de la comunidad, para lo cual examina actas de entrega y cartas de agradecimiento de las comunidades.

Respecto de este punto, existe un caso que nos llama la atención, contenido en la Resolución No 09625-2-2019, en la cual se analiza un supuesto en el que una empresa minera realiza gastos de responsabilidad social, pero para ello, no efectúa directamente la entrega de los bienes y servicios a las comunidades, sino que contrata a un tercero para qué este realice tal entrega y luego le reporte sus actividades. Por este motivo, la empresa minera contaba como documentación sustentatoria, además del contrato y comprobante de pago respectivos, con informes elaborados por el proveedor sobre las actividades desarrolladas.

$\mathrm{Al}$ respecto, el Tribunal Fiscal mantiene el reparo señalando lo siguiente: 
“De los informes y los consolidados de actividades emitidos por el proveedor a la recurrente se aprecia que detalla las actividades que había realizado en dichos meses tales como programas de visitas personalizadas a principales autoridades y líderes de las áreas de influencia, atención a las emergencias presentadas por las inundaciones, actividades para la toma de mano de obra no calificada contratada con sistema rotativo, donación de útiles escolares, capacitaciones de cómputo a docentes, reuniones con directivos del club de madres para planificar actividades en beneficio de la población, entre otras; no obstante, aquellos no cuentan con alguna constancia de recepción y conformidad por parte de la recurrente ni la fecha en que habría incurrido ello aunado a que no acreditan la realidad de servicios que detallan debido a que no se adjuntó documentación adicional que sustentará la prestación de los mismos.

(...) En tal sentido si bien resultaría razonable que la recurrente hubiera adquirido los servicios observados no presentó medios probatorios o documento sustentatorio suficiente que demostrar a la efectiva realización de las operaciones a qué se refieren los comprobantes de pagos emitidos en los términos expuestos en ellos a pesar de que fue requerida por la administración" (el resaltado es nuestro).

Debe notarse que, en este caso, la relación contractual es entre la empresa minera y su proveedor, por lo que, en principio, debería bastar la documentación emitida con motivo de dicha relación como los informes que éste presentó sobre el trabajo realizado. Sin embargo, tanto la SUNAT como el Tribunal van más allá, solicitando que se acredite, además, que el proveedor, es decir un tercero, efectivamente entregó los bienes y servicios a las comunidades.

F. Documentación de soporte

Habiendo revisado los criterios antes mencionados, consideramos conveniente que, a efecto que las empresas sustenten el gasto por entrega de bienes y servicios a las comunidades, deban:

a. Contar y conservar documentación de sustento antes, durante y después de la entrega de los bienes y servicios. Así, por ejemplo: (i) antes: las cartas o comunicaciones de las comunidades solicitando determinado bien o servicio, (ii) durante: actas de entrega, videos, planillas con firmas de los asistentes a talleres, etc, (iii) después: cartas de agradecimiento, menciones en medios de comunicación de la localidad, entre otros.

b. Establecer claramente en los documentos de la empresa tales como el Estudio de Impacto Ambiental, los planes de relaciones comunitarias, 
plan de cierre de minas, entre otros, los lineamientos adoptados para gestionar las entregas y gastos de gestión social.

c. Verificar que la población o comunidad que recibe los bienes y servicios pertenezca al área de influencia de la actividad extractiva de la empresa que realiza la entrega. De no pertenecer propiamente al área de influencia, tener documentado los motivos por los cuales resulta necesario hacer entrega de bienes y servicios a tales poblaciones.

d. De ser el caso, intentar documentar los casos de conflicto, mediante noticias, inspecciones fiscales y policiales.

e. Documentar también el éxito de las medidas tomadas, es decir, demostrar cómo así las entregas de bienes y servicios tuvieron como resultado la aceptación de la actividad extractiva en la localidad, por ejemplo, a través de encuestas de satisfacción realizadas antes y después de las entregas.

\section{iii. Mantenimiento y mejoramiento de carreteras}

Como indicamos anteriormente, en el Perú, la mayoría de las actividades extractivas se realizan en lugares alejados de las zonas urbanas en las cuales, la mayoría de las veces, no se cuenta con vías de acceso idóneos para realizar cualquier tipo de actividad.

Es por ello que, en nuestra experiencia, uno de los principales anhelos de las comunidades aledañas a los sitios donde las empresas desarrollan ese tipo de actividades, es justamente poder contar con una vía adecuada que les permita conectarse con otros lugares del Perú utilizando vehículos de transportes. Y es que, en la mayor parte de casos, lo que se suele encontrar son caminos ancestrales de tierra que no permiten el paso de vehículos y a veces, ni siquiera eso.

Ahora bien, contar con vías de acceso adecuadas también es una necesidad de las empresas extractivas que requieren movilizar a sus trabajadores, contratistas, llevar componentes de la infraestructura al sitio del yacimiento, mover maquinaria pesada y sacar el mineral, entre otros, lo que en buena cuenta significa que el tener estas vías en condiciones óptimas resulta necesario para la ejecución de sus actividades generadores de ingresos gravados con el Impuesto a la Renta. Estas vías suelen encontrarse fuera de los terrenos superficiales de propiedad de la empresa destinados a su propio proyecto, es decir, no se trata de vías que se encuentran dentro de propiedad privada sino de vías públicas y en terrenos de propiedad de terceros (del Estado Peruano y bajo la autoridad de Provias Nacional o alguna municipalidad).

Teniendo en cuenta lo anterior, los desembolsos que incurran las empresas para mantener o mejorar una vía, como carreteras y caminos, estarán vinculados con las actividades propias e indispensables para la realización de sus actividades, tanto 
porque le permitirá mantenerse en buenas relaciones con la comunidad adyacente al yacimiento como porque le dará la posibilidad de ejecutar propiamente su actividad extractiva.

En tal sentido, tales desembolsos no constituyen una liberalidad y sí, por el contrario, cumplen con el principio de causalidad y deberán ser considerados como gasto deducible para efectos del Impuesto a la Renta de la empresa.

Sin embargo, esta conclusión no es compartida por la SUNAT, quien suele reparar este tipo de gastos por considerarlos liberalidades y podría, además, no ser compartida tampoco por el Tribunal Fiscal quien ha tenido una línea jurisprudencial no uniforme. Por su parte, el Poder Judicial (especialmente la Corte Suprema) ha mantenido una línea unánime favorable consistente en aceptar la deducibilidad del tipo de gastos bajo comentario.

Con este objetivo, en el siguiente punto revisaremos los pronunciamientos emitidos tanto por el Tribunal Fiscal como por el Poder Judicial específicamente sobre este tipo de desembolsos.

\section{A. Evolución de pronunciamiento del tribunal fiscal}

Para empezar, debemos tener presente que mantener o mejorar un camino o carretera no implica la creación de una nueva, sino la realización de trabajos que, en el primer caso permitan que se siga utilizando la vía en las condiciones en que fue elaborada mientras que en el segundo caso implica modificar las características existentes de la vía para elevar sus estándares ${ }^{15}$.

15 De acuerdo con el "Glosario de términos de uso frecuente en los proyectos de infraestructura vial”, aprobado por Resolución Directoral N 02-2018-MTC/14, se entiende por mantenimiento y mejoramiento lo siguiente:

- MANTENIMIENTO o CONSERVACIÓN PERIÓDICA: Es el conjunto de actividades, programables cada cierto período, que se realizan en las vías para recuperar sus condiciones de servicio. Estas actividades pueden ser manuales o mecánicas y están referidas, principalmente, a: i) reposición de capas de rodadura, reciclado de pavimento, recapeo, colocación de capas nivelantes, tratamientos superficiales y sellos, ii) aplicación de soluciones básicas, técnicamente evaluadas y ambientalmente sostenibles, en las capas de rodadura, iii) reparación puntual de capas inferiores del pavimento, iv) reparación puntual de: túneles, muros, sistema de drenaje, elementos de seguridad y señalización, v) reparación puntual de la plataforma de la carretera, que puede incluir elementos de drenaje y actividades que contribuyan a la estabilidad de la misma, y vi) reparación puntual de los componentes de los puentes, tanto de la superestructura, como de la subestructura. Este tipo de actividades se realizan por la modalidad de ejecución presupuestaria directa o indirecta; siendo que, en este último caso, se sustentarán en términos de referencia formulados en base a los "Estudios de Mantenimiento o Conservación Vial por Niveles de Servicio" o en "Criterios Básicos de Ingeniería", previamente aprobados.

- MANTENIMIENTO O CONSERVACIÓN RUTINARIA: Es el conjunto de actividades que se realizan en las vías con carácter permanente para conservar sus niveles de servicio. Estas actividades pueden ser manuales o mecánicas y están referidas, principalmente, a labores de limpieza, bacheo y perfilado de la plataforma, roce y limpieza del derecho de vía, limpieza general del sistema de drenaje, mantenimiento de la señalización y elementos de seguridad vial, eliminación de derrumbes de pequeña magnitud; así como, limpieza de juntas de dilatación, elementos de apoyo, pintura y drenaje en la superestructura y subestructura de los puentes. Este tipo de actividades se realizan por la modalidad de ejecución presupuestaria directa o indirecta; siendo que, en este último caso, se sustentarán en términos de referencia 
Con relación a los gastos vinculados con el mejoramiento y mantenimiento de carreteras, el Tribunal Fiscal ha venido trazando una línea jurisprudencial que, en su mayoría, tiende a no reconocer la causalidad de este tipo de gastos.

En tal sentido, el Tribunal ha enfatizado en diversas resoluciones, siguiendo la misma opinión esbozada por la SUNAT, que la deducibilidad de este tipo de desembolsos depende de que se acredite que el trabajo de mejoramiento de carretas sea "extraordinario" e "indispensable", como, por ejemplo, como consecuencia de haber sufrido un desastre natural. Así, ha negado en varias ocasiones la deducción de gastos por mantenimiento de carretera de carácter rutinario o periódico, argumentando que ello correspondía a entidades estatales, aun cuando con posterioridad, el Poder Judicial ha fallado en la Corte Suprema a favor de los contribuyentes permitiendo la deducción de este tipo de gastos cuando se demuestra que resultan necesarios para la operatividad de la empresa.

Asimismo, el Tribunal Fiscal ha considerado en diversas resoluciones, que no debe tratarse de una obra de infraestructura para beneficio de la comunidad a cargo del Estado, pues en ese supuesto constituiría una liberalidad al no existir obligación para asumir dicho gasto. Es decir, desconociendo el hecho que, en muchos casos, el mejorar o mantener caminos y carreteras forma parte de las exigencias de las comunidades aledañas a los yacimientos que deben ser satisfechas por las empresas para poder desarrollar sus actividades en paz.

Como ejemplo de lo anterior, podemos mencionar las siguientes resoluciones del Tribunal Fiscal:

Resolución Nº4807-1-2006:

“Que en opinión del órgano competente (MTC) los gastos por concepto de mantenimiento de carreteras no se encuentran dentro del supuesto previsto por el inciso d) del artículo 72 de la LGM. Que de acuerdo con el expediente Técnico de Mantenimiento de la Carretera presentado como prueba por la recurrente (...) se concluye que los mismos no son gastos de carácter extraordinario y suponen, por el contrario, una actividad periódica para la conservación de dichas vías, la que corresponde ser efectuada por entidades estatales.

formulados en base a los "Estudios de Mantenimiento o Conservación Vial por Niveles de Servicio" o en "Criterios Básicos de Ingeniería”, previamente aprobados.

- MANTENIMIENTO VIAL: Conjunto de actividades técnicas destinadas a preservar en forma continua y sostenida el buen estado de la infraestructura vial, de modo que se garantice un servicio óptimo al usuario; puede ser de naturaleza rutinaria o periódica.

- MEJORAMIENTO: Ejecución de las obras necesarias para elevar el estándar de la vía mediante actividades que implican la modificación sustancial de la geometría y de la estructura del pavimento; así como la construcción y/o adecuación de los puentes, túneles, obras de drenaje, muros, y señalizaciones necesarias. 
Que habiendo asumido la recurrente la realización de un gasto de mantenimiento rutinario y no extraordinario que corresponde ser efectuado por un tercero, se establece que ello constituye una liberalidad de la empresa y en consecuencia no es gasto deducible" (el resaltado es nuestro).

Resolución N 13558-3-2009

"Si bien la contribuyente sostiene a lo largo del procedimiento de fiscalización y en el contencioso tributario, que la realización de esta obra ha significado un incremento en sus ingresos, lo que atribuiría el carácter indispensable para la realización de la actividad gravada, no ha presentado el sustento que acredite de manera fehaciente su dicho, a efectos de definir la necesidad del gasto, y que no se trata de una obra a cargo del Estado, que al beneficiar a la comunidad, constituye un acto de liberalidad; siendo en todo caso que si la construcción ha mejorado el volumen de importaciones y exportaciones, el beneficio económico ha sido obtenido por todos aquellos involucrados en dichas actividades y no solamente por la recurrente, que es la que incurrió en parte del gasto" (el resaltado es nuestro).

Así también, se tiene que se ha aceptado la deducción de este tipo de gastos cuando se realizan como consecuencia del cumplimiento de una obligación con el Estado Peruano. En efecto, en la Resolución N 18397-10-2013, el Colegiado concluyó lo siguiente:

"(el) Convenio Marco para el desarrollo de la provincia de Espinar", respecto del proyecto Tintaya-Sulfuros celebrado entre la Compañía y el alcalde de la Municipalidad Provincial de Espinar, es la materialización del compromiso asumido previamente por la recurrente con el Estado con motivo del otorgamiento de la Concesión por lo que las erogaciones materia de cuestionamiento no constituyen cantidades satisfechas sin contraprestación alguna por parte de los beneficiarios de dicho Convenio Marco - los que son representados por el Estado Peruano-, lo que se enmarca dentro de la exigencia constitucional de actuar con responsabilidad social empresarial, verificándose en consecuencia la relación de causalidad exigida por el primer párrafo del artículo 37 de la Ley del Impuesto a la Renta, con lo cual dichos gastos no responden a liberalidades o donaciones"(el resaltado es nuestro).

No obstante lo anterior, recientemente, en la Resolución N 8425-10-2018, se ha sostenido que las erogaciones bajo análisis son deducibles en tanto sean necesarias para continuar desarrollando la actividad empresarial indicándose que podrían haber:

“condiciones climatológicas adversas que impidiesen la utilización de la carretera con normalidad y que por algún motivo no pudiesen ser 
atendidas oportunamente por las entidades estatales, resultando en tal caso indispensable que la empresa se viese obligada a realizar la rehabilitación, reparación o mantenimiento de la carretera, para continuar utilizándola a efecto de atender inmediatamente los imprevistos que pudieran presentarse en relación al buen funcionamiento de la mencionada central hidroeléctrica". Al respecto, pareciera que el Tribunal Fiscal está flexibilizando su criterio y permitiendo recién la deducibilidad de este tipo de desembolsos ante la inacción del Estado y el carácter "indispensable" de la vía para el funcionamiento de la empresa.

En esa misma línea, en la Resolución N 1011-3-2018, el Tribunal Fiscal indica que, según su análisis, las facturas del proveedor de la recurrente correspondían al servicio de mantenimiento y rehabilitación de acceso a Huallanca, y al de mantenimiento y rehabilitación del acceso Contonga - San Marcos; al respecto, indica que los referidos gastos:

"no responden a actos ausentes de motivación empresarial que impliquen un acto de liberalidad, ya que se incurrió en los mismos a fin de que las actividades de la recurrente se efectúen con regularidad y garantizar la continuidad de aquellas, pues de encontrarse las carreteras en mal estado se dificultaría el traslado de los trabajadores, de los minerales que comercializa, entre otros, lo que impediría el normal desarrollo de sus actividades generadoras de renta, por lo que tales gastos tienen el carácter de indispensables"; debido a ello, el Colegiado procedió a levantar el reparo.

Como parte de esta flexibilización debemos mencionar, sobre todo, la Resolución N³244-9-2019, en la que se discutió el caso de una empresa minera que realizó trabajos de mantenimiento en una carretera que permitieron el tránsito de vehículos pesados con materiales de construcción para la mina, así como de maquinaria pesada. En este reciente caso, el Tribunal Fiscal no analizó si el gasto era extraordinario ni si tenía como origen el que haya ocurrido un desastre natural, sino que simplemente concluyó que el gasto por "mantenimiento" de carreteras "no corresponde a actos ausentes de motivación empresarial que no cumple con el principio de causalidad, pues se incurrió en ellos con la finalidad de que las actividades de la recurrente se efectúen con regularidad y garantizar la continuidad de aquellas pues de encontrarse la carretera en mal estado se dificultaría el traslado de los bienes que adquiere, el personal que labora y los minerales que comercialice (...)."

Sin embargo, es pertinente mencionar que en la Resolución № 9780-1-2019 el Tribunal Fiscal ha recurrido a sus antiguos pronunciamientos a fin de exigir a los gastos por mejoramiento de un puente el carácter de extraordinarios e indispensables a fin de que estos puedan ser deducibles por la empresa que incurrió en los mismos. 
En conclusión, como se puede apreciar de lo expuesto, el Tribunal Fiscal ha venido sosteniendo mayoritariamente que, para que los gastos por mejoramiento o mantenimiento de carreteras sean causales, estos deben ser "extraordinarios" (como consecuencia de un evento o desastre natural), "indispensables" y no constituir una obra pública en beneficio de la comunidad. No obstante, existen únicamente algunos pronunciamientos que se apartan de este análisis y admiten la deducibilidad de gastos vinculados con vías públicas cuando resultan indispensables para garantizar la continuidad de las actividades de la empresa.

B. Pronunciamiento del Poder Judicial

Por su parte, en cuanto a los pronunciamientos del Poder Judicial, este ha reconocido de forma unánime que los gastos por mejoramiento/mantenimiento de carreteras pueden ser causales, indicando que resultan necesarios para mantener su actividad generadora de renta y que se encuentran ligados a la actividad minera.

Es importante hacer mención a la Casación 2743-2009, en la cual la Corte Suprema concluyó expresamente que los gastos efectuados por mantenimiento de carretera y/o mantenimiento resultaban necesarios para mantener la actividad generadora de renta y se encuentran ligados a la actividad minera que desempeñaba una empresa minera.

La referida Sentencia también concluyó que el principio de causalidad no debe interpretarse en un sentido restrictivo, sino en sentido amplio dentro de los márgenes de la normalidad, razonabilidad y generalidad siendo que la normalidad debe entenderse como gasto que sea inherente y habitual de la empresa. Asimismo, señaló que dicho principio no exige que un gasto, para ser deducible, deba ser obligatorio por mandato legal, ni que deba corresponder al objeto social de la empresa, así como que la actividad que origina el gasto no sea también desarrollada por el Estado.

En ese sentido, enfatizó que el carácter extraordinario y no rutinario de un gasto, así como que correspondan ser realizados por terceros como el Estado, a través del Proyecto Especial de Infraestructura de Transporte Nacional devienen en exigencias que no se desprenden del propio artículo 37 de la LIR.

De igual forma, en las Casaciones Nos. 07263-1-2004 y 600-2007 el mencionado órgano judicial señaló que los desembolsos por mantenimiento de un canal son gastos deducibles por ser indispensables no sólo para la zona sino para la empresa que incurrió en los mismos pues de ello dependía la continuidad de sus operaciones y la obtención de mayores recursos hídricos y por tanto ingresos. 
Sin perjuicio de los pronunciamientos anteriores, emitidos por la máxima instancia judicial, debemos mencionar el caso aislado en segunda instancia de la Apelación $N^{\circ}$ 9177-2013, en la que se señaló que no se puede equiparar el mantenimiento de las pistas y/o carreteras por el desgaste ocasionado por su uso ordinario, y que está a cargo del Estado, con la reparación de estas áreas originada por hechos imprevistos y extraordinarios, que pudieran perjudicar el transporte de minerales por parte de la actora. En tal sentido, se concluyó que el criterio de extraordinariedad del gasto era un requisito para la deducción del gasto correspondiente. Debe tenerse en cuenta que éste no es un criterio de la Corte Suprema y es el único caso identificado en contra.

C. Posibles riesgos

Teniendo en cuenta los pronunciamientos mencionados en los puntos anteriores, toda empresa debe tener en consideración que, si deduce los gastos vinculados con las acciones para realizar el mantenimiento o mejoramiento de vías, en una eventual fiscalización la SUNAT podría pretender aplicar los criterios establecidos por el Tribunal Fiscal en la mayoría de sus resoluciones, esto es, que los gastos: i) sean extraordinarios, esto es, que respondan a acciones que no tengan el carácter de permanencia ni continuidad y que se realizarán por única vez, en especial vinculado con desastres naturales; (ii) resulten indispensables para la empresa, es decir, que sin no se efectúan estas acciones, la continuidad y la operatividad de la empresa se vería afectada o incluso impedida; y, (iii) que no constituyan una obra de infraestructura pública que beneficia a las comunidades que se encuentran ubicadas en las zonas de influencia de la obra.

De no cumplirse con tales criterios, es muy probable que la SUNAT formule un reparo respecto de los gastos deducidos, lo cual podría ser confirmado por el Tribunal Fiscal ante la interposición de un recurso de apelación para cuestionar este tema ante dicho órgano colegiado, considerando los criterios antes expuestos que son recogidos mayoritariamente en las resoluciones del Tribunal.

Por lo expuesto, en el eventual caso que no se obtenga un pronunciamiento favorable ante el Tribunal Fiscal, la empresa debe tener en cuenta que tendrá que recurrir al Poder Judicial, puesto que en dicha instancia es bastante probable que la impugnación sea favorable debido a que la Corte Suprema ha concluido favorablemente a favor de la deducibilidad de este tipo de gastos en las sentencias en las que analizó este tema.

D. Documentación de sustento

De la revisión de los pronunciamientos antes mencionados, vemos que, a efectos de sustentar la causalidad de los gastos vinculados con el 
mantenimiento o mejoramiento de caminos y carreteras, las empresas deberían contar, entre otros documentos, con lo siguiente:

- Actos administrativos emitidos por la autoridad estatal titular del proyecto de mantenimiento y/o mejoramiento de caminos y carreteras donde conste su autorización a favor de la empresa para que ésta ejecute las acciones necesarias;

- Convenio de cooperación con la autoridad estatal y la empresa, en la que se contemplen las acciones de mantenimiento y/o mejoramiento de caminos y carreteras

- Contratos con los proveedores suscritos en ejecución del convenio de cooperación antes mencionado que contenga las obligaciones directas entre tales proveedores y la empresa;

- Informes técnicos sobre derrumbes, aniegos, o inexistencia de una vía adecuada para el tránsito de los vehículos pesados;

- Documentación que permita acreditar la imposibilidad de la autoridad estatal de ejecutar el mejoramiento/mantenimiento;

- Documentos técnicos que demuestren el carácter indispensable de la vía de acceso para el transporte de los bienes y servicios;

- Documentos que acrediten que las vías por reparar resultan indispensables para el traslado de personal y equipo necesario, como reportes de accidentes, informes de imposibilidad de paso, entre otros;

- Documentos que acrediten compromisos con las comunidades para la realización de las Acciones para el mantenimiento y/o mejoramiento de caminos y carreteras para mantener el actual clima de aceptación del Proyecto y evitar conflictos sociales futuros, por ejemplo, actas de mesas de diálogo, frentes de defensa locales, etc.

Adicionalmente a lo antes señalado, una vez que la empresa haya efectuado las acciones para el mantenimiento y/o mejoramiento de caminos y carreteras, deberá, además, contar con documentación que le permita demostrar que, efectivamente, realizó tales actividades y demostrar así, la fehaciencia de sus gastos.

A tal efecto las empresas deberán contar con información/documentación como, por ejemplo: valorizaciones, contratos de alquiler de maquinarias, documentos que acrediten la supervisión de trabajos de reparación de carreteras, facturas de adquisición de bienes y servicios, reporte de movimientos contables, memoria descriptiva de proyecto, recortes periodísticos, copias de páginas web, presupuestos, informes de avances de obra, entre otros. 


\section{Conclusiones}

i. En el Perú, las empresas que desean realizar actividades extractivas necesitan tener buenas relaciones con las poblaciones aledañas a los lugares donde desarrollarán tales actividades, para ello incurren en una serie de gastos que buscan evitar los impactos generados por el escalamiento de conflictos sociales, y contar con el consenso social con la comunidad y el entorno en el que desarrollan sus actividades.

Asimismo, estas empresas incurren en ciertos gastos con motivo de cumplir con obligaciones contraídas con motivo del inicio o ejecución de sus actividades, tanto con el Estado Peruano a través de instrumentos tales como el Estudio de Impacto Ambiental, el Plan de Cierre de Minas, entre otros, así como con las poblaciones aledañas, a través de los acuerdos suscritos a través de Mesas de Diálogo, Actas de Compromiso, entre otros.

ii. Existen varias formas de hacer deducibles los gastos antes mencionados para efectos del Impuesto a la Renta, entre las que se encuentran, entre otros, el régimen contenido en el numeral $\mathrm{x}$ ) del artículo $37^{\circ}$ de la LIR referido a donaciones, la deducción de gastos por inversiones en infraestructura a que se refiere el artículo $72^{\circ}$ de la LGM y la deducción de los gastos en aplicación del principio de causalidad.

iii. En el caso del régimen contenido en el numeral x) del artículo $37^{\circ}$ de la LIR, se debe cumplir una serie de requisitos y formalidades a efectos de hacer deducible el gasto por donación. Cabe señalar que puede acudirse a este régimen en tanto la población o comunidad a la que se dirige la donación, se sienta representada por las autoridades estatales del lugar o que se encuentre organizada en entidades inscritas en el registro de entidades perceptoras de donaciones de la SUNAT.

iv. El régimen contenido en el artículo $72^{\circ}$ de la LGM, que permite la deducción de gastos por inversiones en infraestructura, puede ser empleado únicamente por las empresas mineras, siendo que, desde su creación, no ha sido muy utilizado.

v. Los gastos materia del presente trabajo pueden ser deducibles en aplicación del principio de causalidad previsto en la LIR toda vez que resultan necesarios para la evitar conflictos sociales que pongan en peligro la actividad de la empresa, así como la seguridad de sus activos y trabajadores.

vi. En cuanto a la entrega de bienes y servicios por parte de las empresas extractivas a las comunidades aledañas al sitio donde realizan sus actividades, debe tenerse en cuenta que originalmente el Tribunal Fiscal no admitía la deducibilidad de este tipo de gastos por calificarlos como liberalidad. No obstante, últimamente el Colegiado viene aceptando la deducibilidad de este tipo de gastos reconociendo su causalidad, pero 
exigiendo que se pruebe la fehaciencia de éstos, esto es, que se demuestre la entrega efectiva de los bienes y servicios a los destinatarios.

vii. En cuanto a los gastos por mantenimiento y/o mejoramiento de caminos, carreteras y canales, el Tribunal Fiscal ha venido sosteniendo mayoritariamente que, para que estos gastos sean causales, deben ser "extraordinarios, "indispensables" y no constituir una obra pública en beneficio de la comunidad, siendo que existen únicamente algunos pronunciamientos que se apartan de este análisis y admiten la deducibilidad de gastos vinculados con vías públicas cuando resultan indispensables para garantizar la continuidad de las actividades de la empresa.

viii. Por su parte, el Poder Judicial ha reconocido que estos gastos pueden ser causales, indicando que resultan necesarios para mantener la actividad generadora de renta y que se encuentran ligados a la actividad que desarrolla la empresa extractiva. 